\title{
USOS E ACUSOS DA "POLITICAGEM": elites locais e associativismo no Cariri paraibano
}

\section{"POLITICAGEM" AND ITS SOCIAL MEANINGS: elites and associativism in the region of Cariri ( Paraiba/Brazil)}

\author{
Valdênio Freitas Meneses \\ Professor na Faculdade Maurício de Nassau, departamento de Direito, Campina Grande-PB \\ Doutor pelo Programa de Pós-Graduação de Ciências Sociais em Desenvolvimento, Agricultura e \\ Sociedade (CPDA/ UFRRJ) \\ valdeniofmeneses@gmail.com
}

\section{Resumo}

O artigo analisa relações de poder entre elites locais e associativismo na região do Cariri paraibano. O debate é construído em torno dos sentidos que agentes sociais dão a palavra "politicagem", termo usado para falar de uma rede de relações de poder entre sócios, funcionários e lideranças de associações de caprinocultores e que posiciona um projeto de desenvolvimento e políticas públicas em um mapa de disputas eleitorais. Ao analisar a condição de líderes de associação enquanto "mediadores sociais da politicagem" é perceptível contradições e negociações de conflitos quando a bandeira do associativismo é tensionada em engajamentos com deputados, prefeitos, vereadores e famílias de " tradição" política no Cariri.

Palavras-chave: Politicagem. Políticas públicas. Elites. Associativismo. Cariri Paraibano.

\begin{abstract}
The article analyses the relations between political elites and the associativism inside policies for goat livestock in the region of Cariri Paraibano. The arguement is constructed about the social meanings of the word "politicagem" and which values the social agents uses for your engagement at some conflicts that involves employees and partners of goat farm associations in the centre of political-electoral disputes. Seeing the leaders of the associations as social mediators allows understand the contradictions over the idea of rural associativism and how it is negotiated in a local network of power relations.
\end{abstract}

Key words: Politicking. Elites. Associativism. Cariri Paraibano. 


\section{Introdução}

Durante três anos de pesquisa (2011-2014) entre associações de caprinocultores na região do Cariri da Paraíba, ouvi várias vezes a palavra "politicagem". Essa palavra geralmente era evocada para descrever um cenário cortado por conflitos, "traições", intrigas eleitorais, acusações de corrupção e "fofocas" que circulavam numa rede de pessoas: de presidentes e sócios das associações e cooperativas com prefeitos, vereadores, deputados estaduais e famílias com "tradição política" que disputavam o cenário eleitoral dos municípios do Cariri paraibano.

Este artigo é resultado de uma revisita a esses dados de pesquisa que deram origem a uma dissertação de mestrado, apresentada em 2014, e que fundamentaram também o caminho para uma tese de doutorado, conclusa em 2018. A principal proposta é pensar questões sociologicamente relevantes sobre o termo "politicagem" e, assim, entender um recorte de conflitos dentro de transformações sociais e políticas recentes no meio rural do interior nordestino. Essas transformações fizeram com que boa parte da região atualmente conhecida como semiárido, outrora ligada a produção exportadora do algodão junto a pecuária e relações de moradia/trabalho na grande propriedade rural, chegasse ao século XXI, com uma dimensão rural-urbano bastante diversificada, principalmente na relação com os setores mais pobres da população rural. Essa tendência seguiu em todo semiárido nordestino também se na área conhecida como "Cariris Velhos" que desde os anos 19901 é delimitada em microrregiões ocidental e oriental do Cariri paraibano (Mapa 1).

A região do Cariri acompanhou um processo registrado por Buanain e Garcia (2013, p.218) em todo semiárido em que foram consolidadas aos poucos as garantias da Constituição de 1988 quanto ao combate a pobreza rural. Primeiro nos anos 1990 se seguiu uma tendência de uma fragmentação fundiária e criação de assentamentos, com ocupações e desapropriações de terras de centenárias fazendas². Já na década de 20002010 há uma construção de rede de crédito para agricultura familiar (PRONAF), com políticas ambientais, de estrutura agrária e demográfica. Exemplo disso são os novos referenciais de ação, como o Territórios da Cidadania e uma rede de políticas públicas para crédito, transferência de renda e programas de combate à fome, como Bolsa Família, Programa Nacional de Alimentação Escolar (PNAE), Programa de Aquisição de 
Alimentos (PAA), aumento real do salário mínimo, dentre outras melhoras no poder aquisitivo dos mais pobres (BACELAR, 2010).

Mapa 1: Cariri paraibano - Nordeste do Brasil

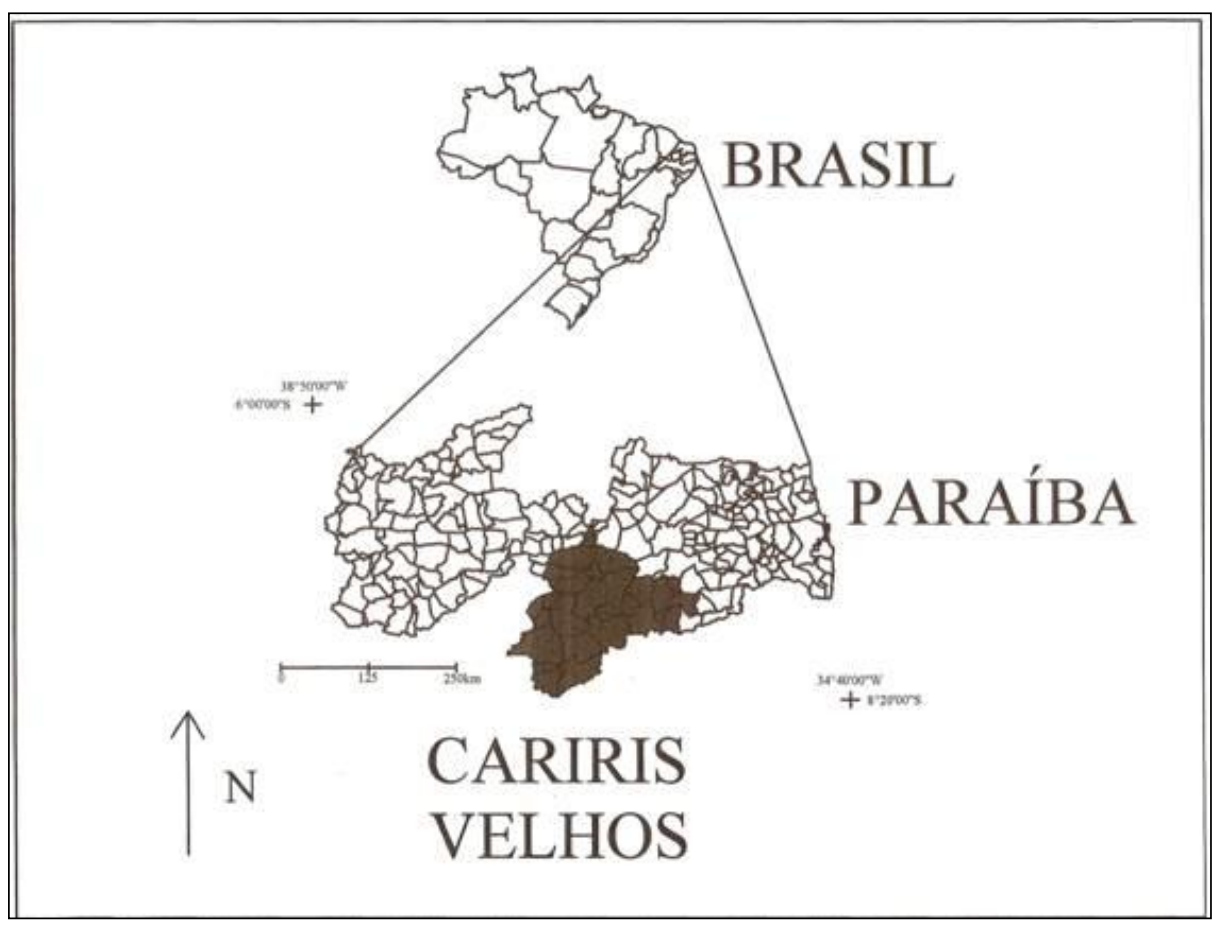

Fonte: SOUZA et al, 2010.

A junção desses fatores é apontada como uma das razões possíveis para a melhora no IDH da região Nordeste com padrões de diminuição da atividade agropecuária nos PIBs municipais, aumento dos recursos de transferência de renda e aposentadorias, e a crescente formalização de empregos na administração pública trazem melhoras para os índices de renda, pobreza e desigualdade - o que, no caso do Cariri paraibano, aconteceu em uma proporção três vezes maior em relação ao total dos municípios brasileiros. (FAVARETO ET AL, 2011, p. 19). Nesse contexto houve a consolidação da proposta de desenvolvimento regional como o Pacto Novo Cariri envolveu entre prefeituras e governos estaduais em torno de políticas públicas de incentivo à caprinocultura e o associativismo rural. (GOMES; MENESES, 2010). Associações se tornaram principal canal de mediação financeira e controle institucional de iniciativas como Programa do Leite, política de compras governamentais controladas a partir de um cadastro de cotas da produção de agricultores familiares (MENESES, 2015, p. 71). 
Em suma, essa conexão de setores públicos e privados em torno do associativismo e políticas de investimento a pecuária caprina (leite e carne) impulsionou uma tendência significativa a criação de associações de criadores de caprinos nos últimos 20 anos:

Tabela 1: Associações e cooperativas de caprinocultores no Cariri paraibano

\begin{tabular}{|l|c|}
\hline \multicolumn{1}{|c|}{ ASSOCIAÇÕES/COOPERATIVAS } & $\begin{array}{c}\text { ANO DE } \\
\text { FUNDAÇÃ̃o }\end{array}$ \\
\hline CAPRIBOM - Cooperativa dos Produtores Rurais de Monteiro Ltda. & 2007 \\
\hline AGUBEL - Associação Gestora da Usina de Beneficiamento de Lácteos & 2004 \\
\hline Laticínio Vila Caroá - São Sebastião do Umbuzeiro & 1997 \\
\hline Associação dos Criadores de Caprinos e Ovinos de Prata & 2001 \\
\hline CAA - Condomínio Agroindustrial de Amparo & 1998 \\
\hline ACCOZA - Associação dos Criadores de Caprinos e Ovinos de Zabelê & 1998 \\
\hline ACAPRIG - Associação dos Caprinocultores de Gurjão & 1999 \\
\hline $\begin{array}{l}\text { ASCOMCAB - Associação dos Criadores de Caprinos e Ovinos de } \\
\text { Cabaceiras }\end{array}$ & 1997 \\
\hline ACCOP - Associação dos Criadores de Caprinos e Ovinos de Prata & 2001 \\
\hline
\end{tabular}

*A Capribom surgiu em 2007 a partir da transformação da associação de caprinocultores de Monteiro (fundada em 1998) em cooperativa.

Fonte: Dados de entrevistas e consulta ao CNPJ das associações no site da Receita Federal.

Com inserção garantida em um mercado institucional de políticas governamentais, o associativismo também teve sua legitimidade política defendida por instituições que atuam na iniciativa pública e privada como Serviço Brasileiro de Apoio às Micro e Pequenas (SEBRAE). Artigos acadêmicos de autores com experiência profissional ligada ao Sebrae- PB apontam que a criação de associações de trabalhadores rurais - caprinocultura, apicultura, pesca, artesanato etc. - seriam uma forma de renovação de formas de ação e decisão coletiva, um "florescimento da participação popular", uma superação de "velhas" formas de fazer política (COSTA; FERREIRA, 2010, p. 44)

Aqui, ao analisar o termo politicagem busco fazer uma contraposição a essa visão bastante eivada de linguagem publicitária sobre a recente onda associativista no Cariri paraibano. Ao fazer visíveis vínculos de elites políticas locais nas associações de caprinocultores do Cariri - através da posição das lideranças - este artigo propõe refletir até que ponto esse "despertar de participação" foi dinamizado por formas de coerção e de subordinação que dão pouco grau participativo para os associados e associações, submetendo-os aos limites das disputas eleitorais e de espaços de poder nos municípios do Cariri paraibano. 
O artigo está dividido em três partes: a primeira está dedicada a "conquista" do tema e objeto da pesquisa, de como teoria e pesquisas sobre fenômeno da corrupção em projetos de desenvolvimento ajudaram a pensar o termo "politicagem" fora de uma ótica normativa - ou seja evitando julgamentos valorativos do termo - mas enquanto lógica de relações sociais que dão sentido a disputas de poder. Nesse tópico também descrevo as fontes que foram utilizadas, o procedimento das entrevistas e os critérios de seleção das associações de caprinocultores analisadas nesse artigo. $\mathrm{Na}$ segunda parte passo para o estudo de caso dos conflitos políticos em torno das associações das cidades de Monteiro e São Sebastião do Umbuzeiro. No último tópico, em tom conclusivo, avanço o debate da politicagem rumo uma leitura dos processos de mediação social das lideranças das associações.

Por fim, importante informar ao leitor que - com exceção das figuras públicas como prefeitos e deputados ligados aos municípios aqui citados - utilizo pseudônimos ao tratar dos nomes de associados e lideranças das associações. Essa escolha é fundamental para privacidade de entrevistados envolvidos em intensos conflitos de "politicagem" dentro das associações de caprinocultores do Cariri da Paraíba.

\section{Notas teórico-metodológicas}

Como sinalizam Bourdieu, Chamboredon e Passeron (2004), a construção de um objeto, a sua demarcação como tema de pesquisa, não é algo dado de imediato e espontâneo: é resultado de uma conquista através de rupturas com o senso comum, novas conexões e recortes com a realidade que perpassam leitura teórica e pesquisa empírica. Ao registrar a palavra politicagem nos meus diários de campo de pesquisas feitas nas associações do Cariri fui acumulando um volume de informações - por vezes dispersas que se tornariam base a posteriori de uma reflexão sociológica de maior fôlego.

Ao tratar da politicagem faço uma operação similar ao que alguns autores, de diferentes matizes, dão ao fenômeno da corrupção. Principalmente no Brasil recente, esse tema foi cercado de alguns mitos e falsas visões envolvem o poder e a relação entre quadros do meio político e empresarial. Mitos esses que foram construídos nos debates acadêmicos mas também em uma espetacularização pela imprensa que elevou ao status de "cruzadas" operações policiais que investigaram crimes de parlamentares e políticos 
do poder executivo nos últimos anos no Brasil. Nesse caldo, foi sendo firmado um primeiro mito sobre corrupção: aquele que coloca dos desvios de conduta em um universo político como sinal de falta de regras - quase como uma anomia nos termos durkheinianos ${ }^{3}$. O fenômeno da corrupção seria resultado de uma suspensão ou ruptura das normalidades. Na esteira de algumas abordagens institucionalistas ${ }^{4}$, essa "falta de regras" de um ambiente institucional corrupto seria um momento de fragilidade das instituições em que agentes racionais maximizadores se apropriariam dos recursos comuns - visão que, por sinal, tende a enfatizar apenas nos desvios de grupos ligados ao Estado, colocando agentes do mercado como naturalmente virtuosos. Uma outra via possível de análise para o mesmo fenômeno, ligada a uma interpretação de clássicos do pensamento social brasileiro, é a corrupção não apenas como "desordem" mas como elemento "cultural" ligado a um patrimonialismo que seria "mal de origem" das heranças ibéricas coloniais. Essa vertente fortemente enraizada no senso comum e sustentada por reinterpretações dos conceitos weberianos nos trabalhos de Sérgio Buarque de Holanda e Raymundo Faoro é duramente criticada em abordagens sociológicas contemporâneas sobre o Brasil (SOUZA, 2015).

Ao tratar da politicagem no campo de estudo me inspiro em estudos sobre corrupção que desmontam esses mitos - e suas cruzadas contra corrupção que tanto tem envaidecido como criado projetos de poder entre procuradores e agentes do judiciário bem como me afasto de leituras que frizam demais em elementos culturais como "camisa de força" para analisar práticas corruptas. Trabalhos fundamentados em pesquisas empíricas ou interpretativa de fenômenos políticos como socioantropologia de projetos de desenvolvimento, Olivier de Sardan (1995) e Blundo e Sardan (2001a, 2001b, 2001c) dão caminhos interessantes para pensar logica da politicagem. Esses autores analisam a corrupção fora de um viés normativo nas interações que envolvem o seu campo de estudo, a burocracia de projetos de desenvolvimento na África ocidental e as lógicas de poder nos espaços locais das comunidades. Através de processos de mediação, solidariedade e reciprocidades que fazem uma cotidiana "economia moral da corrupção", com suas semânticas diferentes "nomes" dados para as práticas corruptas, com fronteiras fluidas entre o legitimo e o ilegítimo. Através das práticas corruptas vemos processos de mediação social entre diferentes níveis de poder, do micro e local ao macro e estatal. 
Mesmo no campo da abordagem neoinstitucionalista propostas que refletem sobre a corrupção saindo do foco excessivo em teorias da escolha racional e suas ligações com desenhos institucionais "oficiais" do Estado ou mercado. Nesse sentido, o livro de Della Porta e Vanucci (2012) The Hidden Order of Corruption é quase um oásis num deserto das análises que legitimam a ilusão de "indivíduos maximizadores" e desenhos institucionais. Com pesquisa focada em documentos ligados a Operação Mãos Limpas (Mani Pulite) que investigou casos de corrupção na relação de empresas e partidos da Itália dos anos 1990 Della Porta e Vanucci (2012, p.2) apontam como o mundo dos desvios e subornos, seja na gestão pública ou privada, não é um estado de natureza Hobbesiano, mas uma ordem oculta de regras e previsibilidades, com códigos invisíveis, normas e reciprocidades entre os atores envolvidos. Assim as variáveis que ajudam explicar a corrupção são vistas não apenas como vetores de dinâmicas externas mas também internas e "normais" das instituições.

Pretendo direcionar um debate sobre o termo "politicagem" em movimento similar a esse feito por autores de epistemologias diferentes para tratar do tema da corrupção: não como desvio de normas ou "falha" cultural mas como mecanismos de regulação social que ora faz concorrência ora tem zonas de conivência aos sistemas ditos oficiais e estatais (leis, sistema jurídico, polícia, mercado etc.). Por isso, classifico um conjunto de relações sociais de poder, caracterizadas no universo de pesquisa das associações do Cariri como "politiqueiras" não como "sintoma" de um anomia, nem indicio de "caos e terra arrasada", evitando um tom de reprovação moral que caracteriza "politicagem" como política de baixo nível ${ }^{5}$. No debate desse artigo as reflexões seguem em uma outra direção: ao qualificar a "politicagem" ou "práticas politiqueiras" nas associações de caprinoculturas do Cariri tento captar nuances de um processo tecido, construído e reconstruído, regulado e regulador, principalmente na disputa cotidiana de poder nos interstícios dos regulamentos oficiais de entidades associativas criada em um forte impulso de transformação social no meio rural do interior nordestino.

A leitura da politicagem também é ferramenta para mapear relações de poder: a politicagem da sentido e explicações aos próprios movimentos ou ao movimento dos adversário, justificando adesões e rupturas com grupos que disputam o tabuleiro eleitoral e político. No cenário aqui pesquisado destacam-se representantes de elites políticas ou de quadros de políticas públicas entre conflitos e sociabilidades cotidianas - tendo como 
epicentro o cotidiano das associações de caprinocultores. Por isso me interessam os processos de mediação na posição das lideranças das associações desde momento das reuniões oficiais até outras sociabilidades menos formais no espaço associativo inspirado e faço exercício comparativo da pesquisa sobre as associações do Cariri com outros casos de estudo na literatura sociológica e antropológica sobre essas organizações rurais: das contradições que envolvem as lideranças associativas rurais no contexto francês (Maresca, 1981) aos estudos de John Comerford (1999, 2003) sobre as organizações associativas e sindicais rurais no interior de Minas Gerais. Esses estudos apontam como as lideranças atravessam desde posições institucionais a níveis cotidianos das associações. Observando esses níveis no caso aqui estudado, é perceptível o quanto a politicagem não é uma coisa, mas um recurso dinamizado entre hierarquias e relações de poder, sejam elas formais (atas, burocracia, reuniões e comitês) ou informais (amizades, parentesco entre associados). A "politicagem" se torna um meio de fluir o poder, recurso que jamais deve ser visto como "coisa", reificado, mas em dimensão multipolar, e relacional distribuído em diferentes graus nas interpendências sociais (ELIAS, 2014, p. $81)$.

Explicado o trato sociológico acerca da politicagem, apresento a seguir a construção da pesquisa. Cito abaixo as fontes para o debate desse artigo foram as seguintes:

- Livros que fazem referência a biografias e memórias das famílias "notáveis" na política local dos municípios de Monteiro e São Sebastião do Umbuzeiro como os de José Rafael de Menezes $(1992,1995)$ e sobre a família Neves, escritos pelo Padre João Jorge Rietveld (1999);

- Notícias de 2006-2011 de blogs locais dos municípios de Monteiro, Sumé e São Sebastião do Umbuzeiro- como Vitrine do Cariri e Cariri Ligado - além de jornais impressos (como O Jornal do Cariri, que circulou até 2004) e notícias veiculadas em documentos do Sebrae-PB;

- Atas de fundação e acompanhamento de reuniões regulares e outros eventos (cursos de capacitação, coleta de leite, vacinação de animais etc.) organizados pelas associações de Monteiro e São Sebastião do Umbuzeiro entre 2012-2014;

- Registro de entrevistas com políticos locais, lideranças e funcionários de associações e usinas de beneficiamento de leite de cabra, políticos e seus assessores 
Com essas informações básicas foram feitas escolhas de pesquisar as associações de caprinocultores de Monteiro e São Sebastião do Umbuzeiro. Monteiro, um município estratégico, pois abriga a sede de agências do SEBRAE e CENDOV, principais referências para caprinocultura e políticas públicas, além de possuir a maior cooperativa de leite de cabra do Cariri: a CAPRIBOM. Já em São Sebastião do Umbuzeiro, cidade bem menor que fica próxima a Monteiro, houve a possibilidade de ampliar o horizonte da pesquisa através de canais de contato com as lideranças das associações de caprinocultores, estabelecidos através de relações de parentesco com pessoas do município.

Para pesquisar a relação das associações com a teia política local desses municípios tive de apreender quais eram os grupos protagonistas do mapa eleitoral. Tomei por base inicial as eleições municipais de 2012 além das articulações entre prefeituras e deputados para entender alguns engajamentos, polarizações e conflitos. Nesse ponto, um exercício que ajudou a delinear quem são as elites ${ }^{6}$ que digladiam por votos no cenário eleitoral dos municípios pesquisados foi a consulta a livros de memórias sobre as cidades e escritos de genealogias escritos das famílias "notáveis" dos municípios do Cariri. São os livros Patriarcas da Alagoa de Monteiro (1992) escritos pelo advogado e político José Rafael de Menezes e Na Sombra do Umbuzeiro (1999) escritos pelo Padre João Jorge Rietveld. Os dois autores elaboram narrativas de fundação dos municípios de Monteiro e São Sebastião do Umbuzeiro e perfilam nomes "notáveis" na história e na política local. Considerando que esses textos não são neutros eles apresentam narrativas sobre elites não apenas no âmbito político-eleitoral mas pautadas em uma distinção através de diversos capitais acumulados (principalmente econômico e cultural) e reconvertidos no recrutamento de candidatos para legitimação frente as disputas eleitorais (CORADINI, 2001, p. 8).

Assim com leitura desses livros de memórias mais as informações obtidas na pesquisa de campo pude me "semialfabetizar" para perceber alguns critérios básicos de quem "tendia ao lado de A ou B" no jogo político-eleitoral local dos municípios. No caso de Monteiro, houve um processo em que famílias de "tradição política" consolidada entre séculos XIX e XX perderam espaço nos últimos 20 anos diante da ascensão do grupo do engenheiro Carlos Batinga que foi prefeito durante dois mandatos (1996-2004) e do empresário da mineração e ex- deputado João Henrique e sua esposa, Edna Henrique que 
foi prefeita de 2008 a 2016. Afirmando estar longe da relação entre política e família, sendo de perfil mais "técnico que político", o grupo encabeçado por Batinga se firmou politicamente com um forte discurso em defesa do desenvolvimento e da caprinocultura e coloca essa "bandeira” (MENESES, 2014a, p. 40). Já em São Sebastião do Umbuzeiro, o laço entre política e parentesco aparece de forma mais decisiva já que protagonizam as disputas eleitorais as famílias Neves - há mais de cem anos identificada com os espaços de oração da igreja católica mas com uma nova geração voltada para a política liderada pelo atual prefeito Francisco Alípio Neves e os Fernandes - encabeçados pela ex-prefeita Fátima Fernandes de uma família de elites proprietárias e pecuaristas (MENESES, 2014a, p. 59).

Estando a par de informações básicas sobre as polarizações político eleitorais dos municípios um outro desafio como pesquisador estava em tentar transitar e dialogar com diferentes interlocutores, mencionando assuntos relacionados à política local e, principalmente, tocando no tema dos conflitos relacionados a "politicagem" nas associações de caprinocultores. Um último dado que me fez seguir um "roteiro" mais ou menos consistente durante a pesquisa foi seguir uma teia de "quem-indica-quem": quando algumas pessoas ao tomarem conhecimento de que eu estava pesquisando sobre a caprinocultura lembravam da figura de ex-prefeitos, vereadores, deputados estaduais e lideranças de associações fui ficando ciente que mais que uma rede de informações, estava acessando uma malha de pessoas e influências políticas em torno das associações e elites locais. Durante a pesquisa eu estava transitando em um tipo de teia amigos-deamigos que negociavam promessas e favores políticos comuns a grupos com maior grau de $\operatorname{poder}^{7}$, redes de interdependência e de distribuição de poder no sentido dado por Norbert Elias (2014, p. 81).

Resumidas alguns referenciais teóricos e recursos metodológicos usados na pesquisa de campo faço, a seguir, uma narrativa mais detalhada de situações de conflito que mostram a tecelagem cotidiana de relações de politicagem que envolveram as associações de Monteiro e São Sebastião do Umbuzeiro. 


\section{O caso de uma cooperativa em Monteiro}

Os conflitos políticos nos quais Antônio Braga - liderança da principal cooperativa de leite de Monteiro, por isso conhecido como Toni da CAPRIBOM evidenciam o "racha" político que existe em torno da disputa de votos pela prefeitura de Monteiro. Trata-se de um embate entre o pessoal instalado na atual secretaria de agricultura de Monteiro, o Centro de Desenvolvimento da Caprinovinocultura (CENDOV) e funcionários da gestão da Capribom. A atual identificação dessas instituições, uma representando "grupo do deputado João Henrique" e a outra "grupo do deputado Carlos Batinga" tem suas origens em algumas mudanças ocorridas no cenário político do município de Monteiro, notadamente a partir da década de 1990. De acordo com os livros de memórias de escritores do município como José Rafael de Menezes (1995), observa-se como os nomes Rafael (posteriormente aliançado com o nome Menezes), Nunes, Falcão, Brito e Gomes ocupam posições administrativas municipais durante todo século XX até o final da década de 1980. Diferente de outras famílias de Monteiro, a família Batinga Chaves não tinha um recrutamento sistemático de seus membros para as disputas eleitorais de cargos políticos. Sendo perfilado como um dos "notáveis" da cidade de Monteiro no livro do escrito José Rafael de Menezes, o pai de Carlos Batinga, Natanael Batinga, é reconhecido mais como quem trabalhou como comerciante local, tentando apenas uma vez ser candidato a vereador em 1992 (MENEZES, 1995, p. 14). E é com essa crença apoiada mais na "técnica que na política" que Carlos Batinga, engenheiro civil, formado pela UFPB e com especializações na área de mobilidade urbana, adentra na década de 1990 nas disputas políticas de Monteiro, e é eleito prefeito em 1996. Este foi um momento em que as famílias dos "bem nascidos" que segundo Rafael de Menezes (1997) tinham um "berço político" (Rafael de Menezes, Santa Cruz, Torres, Falcão etc.) encontravam dificuldades para mobilizar sucessores para as disputas eleitorais. Assim narra o Sr. Jorge Menezes, em frente a "tradicional" farmácia da família localizada no centro da cidade de Monteiro:

Pesquisador - O senhor apoiou Carlos Batinga nas eleições de 1996?

Jorge Menezes - A candidatura de Batinga foi definida numa conversa como essa aqui que a gente tá tendo (...) sentado numa cadeira com o pessoal do prefeito Antônio Nunes na época (...) a gente decidiu colocar o nome do engenheiro Carlos Batinga que parecia ser um nome bom (...) a gente da família tava sem candidato (...) e Batinga era daqui de Monteiro (...) difícil foi convencer ele, pois ele achava que não entendia de política 
Com apoio de boa parte dessas famílias para eleição de 1996, Carlos Batinga enfatizara já no discurso de posse a bandeira de que sua gestão simboliza uma mudança daquele ciclo político, marcado pelas famílias e "apadrinhamentos", passando a ser guiada a partir daquele momento por critérios estritamente "técnicos" (JORNAL SEBRAE, 1999, p. 1-2). Uma outra bandeira da sua gestão como prefeito foi uma proposta de desenvolvimento rural voltada para políticas de combate à seca e fomento a caprinocultura.

Saindo da prefeitura de Monteiro em 2002, Batinga, consegue firmar uma marca política de ter sido um gestor que "trouxe o desenvolvimento" para Monteiro e assim consegue, antes de assumir o cargo de superintendente estadual do SEBRAE, lançar a candidatura vitoriosa das eleições de 2004. Trata-se de sua antiga secretária de saúde, Lourdes Aragão (conhecida como Dra. Lourdinha) que é eleita derrotando o candidato da oposição à Batinga, João Henrique. A figura política de João Henrique, de forma similar à Batinga, também não está legitimada em uma "tradição familiar política" de Monteiro. Sendo natural do município e filho de produtores rurais, João Henrique ficou mais conhecido como um empresário da mineração do mercado da turmalina que redirecionou investimentos e "apostou" no jogo político. Após a derrota nas eleições para prefeito em 2004, João Henrique conseguiu ser eleito deputado estadual nas eleições de 2006. Nesse período o jogo de disputas políticas de Monteiro ficou mais acirrado, na medida em que vereadores da cidade retiraram o apoio a Carlos Batinga, a essa época também eleito deputado estadual, "passando para o lado" de João Henrique.

Polarizado entre partidários dos deputados estaduais Carlos Batinga e João Henrique o cenário político de Monteiro após 2006 tem como uma das principais arenas de disputas as instituições de fomento a caprinocultura: o Cendov e a Capribom. Quando colocado pra falar de conflitos políticos, "Toninho da Capribom" inicia seu argumento alegando que se a caprinocultura leiteira atingiu certo status no Cariri este resulta da "vontade política e da visão empreendedora de Carlos Batinga". Toni também argumenta que a escolha e confiança de Batinga pelo seu nome, na primeira gestão do CENDOV no final da década de 1990, seguiu apenas critérios técnicos, pois ele já tinha experiência como veterinário em assistência voltada para a pecuária.

O processo de "saída" de Toni do cargo de gerência do Cendov para ficar exclusivamente na Capribom esteve ligado diretamente ao desenho de conflitos políticos 
de Monteiro entre os grupos de Carlos Batinga e João Henrique, partirurlamente auqeles cerrado nas eleições municipais de 2008, e que fizeram "rivais" a CAPRIBOM e CENDOV em situações entre 2006 a 2009. Entre esses o mais intenso aconteceu em 2008 quando Toninho tentou se candidatar a vereador e não foi eleito. Na eleição para prefeito saiu vitoriosa Edna Henrique, esposa do deputado João Henrique, com apoio da maioria na câmara municipal de Monteiro. Nas primeiras sessões após as eleições em outubro de 2008, os vereadores que apoiaram a prefeita eleita Edna Henrique partiram para ataques contra o deputado Carlos Batinga e seus "preferidos", como Toni. Um dos vereadores ironizou Batinga usando de uma acusação contra Toni de que este estava instalando postes na zona rural, pedindo votos e fazendo politicagem dentro da cooperativa de leite de cabra. (VITRINE DO CARIRI, 2008)

A partir de 2009, o Cendov passa a funcionar como secretaria de agricultura da gestão da prefeita Edna Henrique e Toni fica integralmente como veterinário na Capribom. Uma relação de rivalidade entre essas duas instituições começa a ganhar contornos, na medida em que Toni se insere ativamente no grupo de oposição à prefeita Edna Henrique nos espaços de decisão envolvem a cooperativa. Exemplo disso foi a situação da paralisação de atividades de um abatedouro construído com recursos de uma parceria com o Projeto Dom Helder Câmara, o, SEBRAE e o Cendov com recursos do MDA (Ministério do Desenvolvimento Agrário), governo estadual da Paraíba. Logo após a inauguração as atividades do abatedouro foram suspensas e este acabou sendo objeto de uma série de disputas e "bate bocas" nas reuniões do CMDRS do município de Monteiro. O presidente do CMDRS, Hildeberto Júnior fala que após a prefeita Edna Henrique assumir o mandato, Toni da Capribom se utilizou de várias manobras políticas: ora forçando agricultores de várias associações de trabalhadores rurais a ir nas reuniões para demonstrar ter maioria nas decisões do conselho ora esvaziando as reuniões e discussões de pautas para suspende-las alegando falta de quórum. Quando pergunto a Toni sobre esse caso do abatedouro ele diz que esse estilo de fazer politicagem não é o dele mas o jeito típico da "da prefeita e do pessoal Cendov":

Toni: Quando começou a gestão dessa prefeita atual eles quiseram intervir aqui na Capribom, saber como era, querendo colocar pessoas aqui (...) fazer politicagem. Simplesmente a gente se reuniu e dispensamos. Hoje aqui a gente faz a gestão própria, gerenciada com os recursos da própria produção dos sócios cooperados. É um negócio dos produtores e a gente dispensa até certos 
subsídios, entre aspas, que geralmente são maldosos e mal intencionados, pra ser cobrado no futuro (...)

Nesses conflitos a cooperativa de leite e suas reuniões associativas acabaram, cada vez mais, sendo organizadas em um grau de hierarquia centralizado na figura de Toni. Na minha própria interação na pesquisa pude ter evidências de como a figura de Toni exerce bastante influência dentro da Capribom. Nas primeiras tentativas de diálogo havia alto grau de desconfiança pois Toni alegava que "já tinha vindo gente disfarçado de polícia pra cooperativa" e que tinha dado problemas em época de eleição - além de acusar que esse "povo de universidade vem aqui e nunca traz nada pra cooperativa". Conseguindo amenizar um pouco desconfiança, a primeira reunião que consegui acompanhar na Capribom foi uma de caráter "informal" com a presença de caprinocultores e de funcionários a frente da usina. $\mathrm{O}$ que estava sendo discutido eram alguns problemas quanto ao transporte do leite de cabra nos tanques de resfriamento que ficam nas localidades mais distantes da zona rural de Monteiro. A questão era mudar os horários em que o caminhão da Capribom passa nos tanques para pegar o leite dos produtores e levar para as usinas. $\mathrm{O}$ discurso dos funcionários era quase que unânime: as demandas, decisões e dúvidas deveriam ser levadas para Toni que não pôde acompanhar a reunião até o final.

A segunda reunião que acompanhei na Capribom ocorreu um dia depois da primeira, no início de agosto de 2013. Esta foi realizada dentro do escritório na presença de funcionários, presidentes e alguns produtores para fazer um balanço dos gastos da usina. Havia uma série de papéis na mesa e estavam presentes a secretária da Capribom, um dos técnicos da cooperativa, um funcionário da contabilidade e dois caprinocultores associados. Antes de começar a reunião um trabalhador da usina chegou com as mãos cortadas e perguntou a Toni se podia ir até à cidade fazer um curativo. De forma ríspida, Toni respondeu para ir rápido e não atrasar a limpeza das máquinas, em seguida pediu para um dos funcionários presentes levar o trabalhador da usina para o hospital de Monteiro. "Aqui você pode ver que a gente tem muito trabalho e não para um instante" falou dirigindo-se a mim. Um detalhe interessante no espaço do escritório da cooperativa era a posição da pilha de documentos e dos funcionários centralizada em Toni, que quase sempre dava a "última palavra" nas decisões da reunião que acabara de encerrar. Essa percepção do Toni como uma figura central me fez pensar que ele era o presidente: 
Pesquisador: Nessa mudança você já era o presidente daqui ou era outro? Toni: Na verdade eu nunca fui presidente daqui. (...) Por eu ser um profissional, geralmente eu exerço cargos de gerenciamento e de assistência técnica, de responsabilidade técnica dos estabelecimentos. A diretoria geralmente é composta por produtor e agricultor familiar. Durante esse período nós já tivemos uns seis presidentes. Diretorias que são renovadas aí de quatro em quatro anos, no caso da associação, da cooperativa, é de quatro... podemos renovar um terço, apenas um terço dos dois conselhos administrativo e fiscal (...).

Um dos produtores que pouco falaram e que estava na reunião era o presidente eleito da Capribom, Fabiano Sousa. Quando perguntei sobre a sua posição de presidente da cooperativa, Fabiano me deu respostas curtas, chamou a atenção para combater o "individualismo do produtor rural" e assinalou que Toninho já tinha falado o bastante. Quando a palavra voltou a Toni ele destacou a sua "luta" para introduzir na Capribom uma gestão privada em que se faz necessário um controle de gastos com relação aos impostos altos que um laticínio precisa pagar. Essa linguagem da luta e do coletivo é reforçada, para defender uma "independência" econômica e principalmente política da cooperativa:

Pesquisador: Tem alguma disputa política dentro da cooperativa?

Toni” A gente nunca fez trabalhos políticos aqui. Tem consciência do que tá fazendo. Tem espaço pra quem vota em A ou B. A gente nunca discutiu sobre isso não (...). Então hoje a gente luta para que o negócio seja privado aqui, independente de política (...).

Toni acusa o grupo político de João Henrique de fazer retaliação a CAPRIBOM pelo fato de que "ele não se vendeu nem fez politicagem". Assim ele justifica a ausência da maior cooperativa de caprinocultores do Cariri paraibano de feiras agropecuárias anuais e exposições organizadas pelo Cendov e instituições parceiras. Quando fui ao Cendov, alguns funcionários justificavam de forma quase uniforme o argumento de que a Capribom não foi chamada para os eventos pois a demanda principal era de privilegiar a agricultura familiar em detrimento da pecuária. Assim, a linguagem de "pecuária melhor que agricultura" era uma "vestimenta técnica" para um embate político entre as tendências representadas pelos grupos em torno de Carlos Batinga e João Henrique.

\section{O caso da associação de São Sebastião do Umbuzeiro}

O cenário político de São Sebastião do Umbuzeiro possui uma polarização identificada com relações de parentesco, rivalizando as famílias Neves e Fernandes. O 
desenho destas disputas foi sendo firmado por rupturas políticas entre membros dessas duas famílias, visando à eleição municipal de 2008, quando o atual prefeito Francisco Alípio Neves (conhecido como Chico Neves ou "Chicolá") venceu o candidato a reeleição Alexandre Fernandes. A trajetória política de Chico Neves até alcançar o cargo de prefeito possibilita visualizar dois aspectos. Há, primeiro, um investimento feito no universo político por alguém de uma geração mais jovem de um grupo familiar reconhecido mais por relações históricas que mantém com a igreja do que com as tramas da "política" propriamente ditas (RIETVELD, 1999). E o segundo aspecto está relacionado ao modo como se processou tal investimento, a partir de uma ruptura de alianças políticas com a família Fernandes que mantinha, desde 1980, o PMDB local unido entre Malaquias Batista (pai de Fátima Fernandes que foi prefeita entre 1996 a 2004) e Metódio Neves (pai de Chico Neves). Sendo vereador eleito em 2000 na mesma base partidária de Fátima e Alexandre Fernandes, Chico Neves iniciou um racha político nas disputas internas que foram travadas pela presidência da câmara municipal de vereadores em 2005. Saindo do PMDB, Chico Neves se filiou ao DEM e consegue vencer as eleições de 2008 contra Alexandre Fernandes. Uma situação exemplar das reverberações de uma nova relação política, não mais de aliança, entre Neves e Fernandes, são os conflitos travados dentro da associação de caprinocultores de São Sebastião do Umbuzeiro.

A Associação dos Produtores das Comunidades Capitão-mor, Salgado, Salão, União, Poço Entupido, Boa sorte e Dois Riachos foi fundada em 1997. O nome de "Vila do Caroá", dado tanto a associação como a usina de beneficiamento e leite, é uma homenagem as antigas fábricas de cordas de Caroá - planta que era bastante comum na região do Cariri paraibano - e que funcionaram entre as décadas de 1940-1960 em São Sebastião do Umbuzeiro. Segundo o primeiro presidente Júnior Neves, a Vila do Caroá foi inicialmente pensada como uma associação voltada para os projetos de eletrificação rural e não para a caprinocultura leiteira. Júnior Neves foi indicado pela então prefeita Fátima Fernandes em 1997 para organizar os trâmites jurídicos e principalmente organizar o coletivo da associação e fazer manutenção do maquinário para beneficiamento de leite na usina. Falando dessa época de dificuldades na manutenção das máquinas na usina, Júnior Neves cita a importância de José Vieira para a Vila do Caroá. José é natural de Paulo Afonso, Bahia e trabalhava "fazendo bicos" na manutenção de 
eletrodomésticos e em oficinas mecânicas de São Sebastião do Umbuzeiro. Júnior afirma que ficou com a parte gerencial da associação, lidando diretamente com os associados, enquanto José Vieira foi contratado para trabalhar na manutenção dos aparelhos da usina. Júnior Neves avalia que foi uma experiência positiva a frente da associação apesar da politicagem:

Júnior Neves: "Olha (...) assim a questão do associativismo não deslancha ainda (...) em virtude da interferência política (...) da política eu digo não é da política sadia (...) é da politicagem quando eu era da presidência da associação (...) eu nunca falava de política (...) dizia "olha vamos tentar não falar em política aqui dentro da associação (...) vamos tratar todo mundo por igual" (...)

O grau de conflito expresso na fala sobre politicagem de Júnior Neves se acentuou após 2006 quando em decorrência da aprovação em um concurso público para a agência do BNB em outra cidade do Cariri, ele teve que abdicar do cargo de presidente da associação e convocou novas eleições, estruturando uma chapa única, encabeçada por José Vieira como presidente. Segundo Júnior, "Zé” já era um "homem de confiança" pelos serviços prestados à usina. No mesmo ano de 2006, o então vereador Chico Neves, acentua a disputa para a presidência na câmara municipal que terá como consequência sua ruptura com a família Fernandes e com o PMDB, seguida da candidatura pelo DEM a prefeito nas eleições de 2008. Júnior Neves narra as dificuldades em manter as alianças políticas com os Fernandes e justificou a relação de parentesco para "sair" do grupo que tinha como candidato Alexandre Fernandes e passar a apoiar o seu parente nas eleições de 2008, sendo este último vitorioso no pleito:

\footnotetext{
Pesquisador - Como foi a sua saída do grupo dos Fernandes?

Junior Neves- Aí veio a eleição pra prefeito [2008] (...) Chico lançou candidatura contra os Fernandes (...) como o candidato era Chico aí nós chegamos pra Alexandre [Fernandes] e falamos (...) olha Alexandre a gente não tem nada contra você, mas pelo fato dele ser nosso parente (...) nós vamos apoiar Chico (...) aí nós rachamos também (...).
}

A saída de Júnior Neves do grupo dos Fernandes inaugurou uma sequência de conflitos com o seu "homem de confiança" na associação Vila do Caroá. Júnior reclama que Vieira além de não apoiar Chico Neves, pediu voto aos sócios e "fez políticagem", a favor dos Fernandes, dentro da associação, durante a eleição de 2012: 
Júnior Neves: Aí veio novamente a questão política para a associação (...) já começou na primeira eleição de Chico (...) Vieira não quis vim pro lado de Chico e ficou do lado dos Fernandes (...) só que quem ganhou a eleição foi Chico (...) e infelizmente não há como a associação usina (...) ou qualquer coisa (...) funcionar em um município como esse (...) sem ter o apoio do poder municipal (...) não tem como (...) é tanto que a usina funciona em um prédio municipal (...) a água é a prefeitura que concede (...) uma parte dos funcionários é paga pela prefeitura (...) a energia elétrica é paga pela prefeitura (...) quando eu era a presidência da associação (...) e a reclamação que eu recebi depois que sai é que Vieira fez muita política dentro (...) pedindo voto e ameaçando os funcionários.

Em uma entrevista, José Vieira expõe o seu ponto de vista argumentando que ele acabou sendo prejudicado por Júnior Neves nesse processo de mudança de "lados". Vieira coloca que até 2008 ele e Júnior faziam uma parceria muito boa para a associação, pois, cada um cuidava da parte que entendia melhor dentro da associação e dos equipamentos da usina. Vieira afirma que até chegou a brincar com a esposa de Júnior que "era um casamento perfeito" para o funcionamento da associação. Contudo, na mudança de gestão na prefeitura, Vieira justifica que apesar de não "viver politicando" acabou sendo alvo de muitos acusações de que a associação era "vermelha do 15" dos Fernandes:

José Vieira - (...) Aí hoje inverteu a posição (...). Júnior já faz parte do governo de (...) de Chico. Algumas pessoas ligadas ao governo de Chico já não querem que eu faça parte disso aqui [a associação] pelo fato de eu já ter trabalhado no passado pelo outro partido (...). E que por coincidência eu acho engraçado. (...). Quando o próprio Júnior saiu, largou os Fernandes, pra fazer parte da equipe do governo

Pesquisador - Não teve nenhum atrito com essa mudança aqui dentro da associação?

José Vieira - Porque aconteceu o seguinte. Ele [Júnior] é muito inteligente (...). Ele fez o seguinte. Eu acho que talvez tenha sido a decisão que ele tomou pra me preservar, preservar ele e a Associação (...). Porém, no frigir dos ovos eu acho que quem ficou com o prejuízo fui eu. (...) Porque? Eu fazia parte do mesmo grupo político que ele. Não que eu vivesse em mei de rua politicando. Mas que, vamos dizer assim, a gente trabalhava na mesma linha, né? Tava ligado. Só que quando ele apoiou... Foi apoiar o parente, ele foi e eu disse "eu vou também". Aí ele disse "não, você fica". Aí ele disse "eu não sei se Chico ganha a campanha, certo?" Eu fui escolhido pra ficar aqui [na associação]. Eu não fui escolhido pra ter a opção (...).

No fim da entrevista, em tom de desabafo, Vieira diz que acabou como o "bode expiatório" da associação dentro da política local da cidade:

José Vieira - E hoje quando se fala em política dentro do município que a gente mora eu não sou benquisto, pela equipe que atua na prefeitura. Eu só não sei lhe dizer com toda sinceridade o motivo (...). Porque eu nunca joguei uma pedrada em nenhum deles (...) Então o que é que aconteceu? O parente de 
Júnior ganhou e a partir de então desde o primeiro dia de mandato de Chico (...) eu só tenho levado burduada de um e de outro (...) já que a gente fala de cabra aqui (...) acabei sendo o bode expiatório (...) até hoje querem me tirar daqui pra poder botar uma pessoa que seja deles (...) e a associação se prejudica com isso (...) como na questão do maquinário para forragens (...).

Depois que a "parceria" com Júnior acabou Vieira acusa a prefeitura de ter "escondido" um maquinário, obtido com recursos do PAC do governo federal em 2011 e que serviria para um melhor processamento de ração e forragem para fornecer aos próprios produtores da usina. Segundo Vieira, isso foi uma politicagem para fazer com que os associados ficassem com "raiva dele" pensando que o não uso das máquinas era culpa do presidente. Assim Vieira acusa a prefeitura de usar as máquinas para funcionar quando estivesse próximo ao período eleitoral nas eleições de 2012, quando Chico Neves foi reeleito.

\section{Considerações finais: os mediadores sociais da politicagem e a encruzilhada do associativismo}

Os casos de conflito das associações de Monteiro e São Sebastião do Umbuzeiro ilustram como a politicagem apresenta as seguintes dinâmicas sociais:

\section{A) Uma forma de interpretar processos e conflitos políticos: a expressão} politicagem é invocada pelos atores envolvidos em um processo político geralmente para tentar explicar situações em que houve embates e negociações de poder entre seus aliados e adversários políticos. Mesmo negando e apontando a "politicagem dos outros" os líderes de associação ao explicar acabam também demonstrando seus próprios engajamentos.

B) A representação da politicagem e as relações de poder na vida cotidiana: a palavra politicagem e a expressão "fazer política" pode ser compreendida como um conjunto de práticas sociais que envolvem os agentes sociais em uma lógica de lealdades ou rupturas nas disputas que envolvem grupos políticos em "locais" estratégicos. Nesse sentido, a politicagem é mais que explicação ou intepretação dos fatos mas um agir, um modus operandi, um senso prático para atacar, defender-se ou negociar dinâmicas de conflito que envolvem o cenário político - as "questões políticas". 
Guiado pela leitura de Sardan (2001), é notável como essa dupla definição de politicagem orienta uma lógica de poder que envolve várias retóricas possíveis, armas de batalha que grupos sociais disputam um dado projeto de desenvolvimento pautado no associativismo. Por exemplo, no caso de Monteiro, a politicagem mobiliza um discurso e autoimagem de "técnicos" que atravessam o atrito entre Capribom e o Cendov, instituições que, por sua vez, representam um cenário polarizado de Monteiro, entre os grupos políticos representados pelos deputados Carlos Batinga e João Henrique. O fator "politiqueiro" evoca nas falas de Toni quando ele nega "fazer trabalhos políticos" mas ao mesmo tempo afirma a eficiência "empresarial" e independência política na Capribom em relação a prefeitura. Se nega fazer política, fazendo-a na forma de acusação: eis o jogo da politicagem. Se acusa na sua fala que há uma forma "suja de fazer política" que não combina com a eficiência técnica ligada ao seu grupo político logo essas falhas seriam típicas do grupo rival que gerou um conjunto de "punições" para a cooperativa, como é o caso da exclusão nos eventos organizados pelo Cendov.

O caso da associação de caprinocultores de São Sebastião do Umbuzeiro, traz algumas particularidades na lógica da politicagem próxima a um eixo de política local e parentesco. Os usos e acusos de "fazer politicagem" na associação Vila do Caroá operam no contexto de disputas políticas do município enraizados na dimensão de pertencimentos aos sobrenomes Neves e Fernandes. A frase dita por um ex presidente da associação: "eu decidi apoiar o então prefeito porque é meu parente" é bastante emblemática. Dita de uma forma espontânea e natural, a afirmação do parentesco tem por consequência um envolvimento direto da associação na batalha político eleitoral e familiar de São Sebastião do Umbuzeiro. A associação passou a ser vista como local de "fazer politicagem" de "ser do lado" de vestir a camisa dos partidos "azuis ou vermelhos", de votar no "25 ou do 15 ". Essa era a linguagem corriqueira para expressar alguns dos conflitos entre presidentes, sócios e funcionários na Vila do Caroá.

A leitura sociológica da politicagem ajuda a guiar o que se chama de um processo de mediação em um processo político que pode ser expresso de diferentes maneiras, podendo ser dita tanto pela gramática técnica modernizante ou do familismo político e a honra de relações pessoais. Os processos de politicagem construídos a partir da pesquisa em Monteiro e São Sebastião do Umbuzeiro evidenciam três vias de formação social de líderes e mediadores sociais: primeiro o trânsito entre os espaços institucionais das 
políticas públicas de estimulo a pecuária caprina no Cariri (reuniões do Sebrae, cursos de capacitação nas universidades e secretárias municipais e estaduais de agricultura etc.) que implica tensões que envolvem a relação projetos de desenvolvimento- beneficiários (NEVES, 2008) e as negociações da linguagem desenvolvimento na arena local( SARDAN,1995). Uma segunda dimensão são negociações de favores e prestações entre elites políticas - a figura do broker (BOISSEVAIN, 1977) - o que implica em negociar mais do que valores materiais ou monetários mas fundamentalmente vínculos sociais de engajamento ou rivalidade que uma associação vai ter diante com um grupo político representado por um deputado ou uma família. Por fim, a politicagem também é negociada em uma dimensão mais de uma sociabilidade lúdica e cotidiana em que os códigos de amizades e parentesco são acionados dentro das afinidades proximidade políticas no cotidiano das associações e sindicatos de trabalhadores rurais (COMERFORD ,1999, 2003).

A título de conclusão destaca-se que ao recortar essas três vias da politicagem no associativismo rural que se intercruzam na posição do líder de associação fica difícil corroborar com aquela hipótese de que o associativismo seria uma "consciência" ativada recentemente e que estava adormecida na região do Cariri. "Dissecar" o que os atores evocam na palavra politicagem leva a problematizar o discurso de instituições como o Sebrae que defendem desde a década de 1990 o modelo de "associativismo para pequenos" junto a caprinocultura no Cariri. Com base na discussão travada nesse artigo pode-se afirmar que a mesma lógica associativista - aquela defendida em artigos de pesquisadores ligados ao Sebrae como avanço de espaços de participação e gestão democrática (COSTA; FERREIRA, 2010, p.43) - é também uma via propícia para articulação de forças políticas que limitam as possibilidades de autonomia e maior participação política. Por parte dos discursos acadêmicos vinculados ao Sebrae, até há um certo reconhecimento de que disputas ligadas a política local têm influência nas associações. Porém, o argumento é que tais disputas, quando ocorrem, são pressões políticas "externas" sobre as associações, projetos e pactos, ou seja, uma tentativa de "sobrevivência" de supostas práticas arcaicas de municípios em que

[...] o prefeito "boicotou" a participação e não aconteceram, sequer, as reuniões iniciais de esclarecimentos aos cidadãos (...) Nessas cidades, as velhas mentalidades e disputas políticas, restritas aos feudos familiares, atravancam as iniciativas de qualquer mudança (COSTA; FERREIRA, 2010, p.46) 
O debate proposto por esse artigo direciona para um caminho diferente de tais afirmações. A politicagem não é uma "velha" mentalidade - com data para terminar nem é exclusiva de feudos familiares. Tampouco se impõe externamente: a politicagem é algo tão interno e inerente que, inclusive, faz "funcionar" a vida política associativa na instabilidade dos conflitos políticos eleitorais. A análise dos casos de conflitos ligados às associações de caprinocultores de Monteiro e São Sebastião do Umbuzeiro que não há "boicote" de prefeitos mas um entrelaçamento dos seus respectivos grupos eleitorais com as lógicas de poder das associações, instituições e programas de incentivo a produção de leite de cabra. Nesse sentido o modelo ideal de agricultor solidário, na ideologia do modelo associativo, como aponta Neves (2005), não é algo "puro" que vem sendo maculado pelos moldes da politicagem. O diálogo com a pesquisa empírica traz o argumento de que o vínculo politicagem/associativismo contém engenhosas articulações políticas que dinamizam níveis das transformações projetadas a partir de um projeto de desenvolvimento para a pecuária caprina, às vezes fornecendo o próprio sustentáculo institucional para a ação pública. Essa sustentação, e até mesmo um elemento de "sobrevivência" das associações, via politicagem pode ser visualizada de forma mais acentuada em fase de fragilidade da articulação do Pacto Novo Cariri, que produziu a força motriz inicial para o modelo de associativismo, e principalmente nos constantes atrasos no pagamento de programas de incentivo a produção de leite de cabra. Como em termos de poder, não existe vácuo, fica o espaço das decisões associativas cada vez mais dependente das relações sociais que seguem a lógica de uma politicagem.

\section{Notas}

\footnotetext{
${ }^{1}$ A atual delimitação do IBGE para o Cariri paraibano é de 1990 e faz uma divisão entre duas microrregiões: Cariri ocidental e oriental.

${ }^{2}$ Esvaziadas pela saída dos moradores para a cidade, pelas secas periódicas e crises econômicas na produção algodoeira, falta de competência ou dificuldades dos herdeiros para gerir as atividades rurais cada vez menos lucrativas. Um marco político desse processo no Cariri paraibano foi a desapropriação da Fazenda Feijão - até o início do século XX pertencia à família Rafael de Menezes e tinha a distinção de ser a maior fazenda pecuarista da região com quase nove mil hectares - para criar o Assentamento Mandacaru, que, desde 1990, abriga 118 famílias (SILVA, 2012, p. 53).

${ }^{3}$ Em dicionários de sociologia o verbete "anomia" tem seu significado sedimentado no pensamento social pelos trabalhos de Emile Durkheim e Robert Merton. Segundo Durkheim no seu Divisão Social do Trabalho a anomia seria "ausência de um corpo de regras governando as relações entre os grupos sociais". Tentando explicar os males do capitalismo industrial, a visão de Merton define anomia não como uma falta de regras mas a um colapso da estrutura cultural com bifurcações entre normas e objetivos culturais e a capacidade dos membros do grupo de agir sob estas normas. (Lukes, 1996, p.20).

4 Sobre os tipos de neoinstitucionalismo ver Hall e Taylor (2003)
} 
${ }^{5}$ Definição do Michaelis: http://michaelis.uol.com.br/busca?id=QwxMy

6 Perissonato e Codato (2008) apresentam um trabalho de revisão sobre o tema e conceito de elites nas ciências sociais. Os autores colocam a sociologia relacional de Pierre Bourdieu - da qual se aproxima este trabalho- como uma reverberação crítica dos debates da Teoria das Elites feita por clássicos como Pareto e Mosca como do marxismo estruturalista.

${ }^{7}$ Toda articulação política local tem uma rede "amigos-de-amigos" como delimita Boissevain (1976, p. 166) em seu trabalho sobre a máfia e o poder local na Itália dos anos 60.

\section{REFERÊNCIAS}

BACELAR, Tania. Economia do semiárido: a crise como oportunidade. Revista Coletiva, n.15 jan-abr, 2010.p. 5-19.

BOISSEVAIN, Jeremy. Friends of Friends: Networks, manipulators and coalitions. University of Amsterdam, Basil Blackwell, 1976.

BOURDIEU, Pierre; CHAMBOREDON, Jean- Claude; PASSERON, Jean Claude C. O ofício de sociólogo: metodologia da pesquisa na sociologia. $5^{\mathrm{a}}$ ed., Pétropolis, RJ:

Vozes, 2004.

BUANAIN, Antônio; DEDECCA. Pobreza rural e desenvolvimento no semiárido nordestino: resistência, reprodução e transformação. BUANAIN, A. M; DEDECCA, C. A nova cara da pobreza rural: desenvolvimento e questão regional, Brasília, IICA, 2013, p. 217-306.

COMERFORD, John Cunha. Fazendo a luta: sociabilidade, falas e rituais na construção das organizações camponesas. Rio de Janeiro: Relume- Dumará: Núcleo Antropologia da Política, 1999.

. Como uma família: sociabilidade, territórios de parentesco e sindicalismo

rural, Rio de Janeiro: Relume- Dumará: Núcleo Antropologia da Política, 2003.

CORADINI, Odacir. Em nome de quem? Recursos Sociais no Recrutamento de Elites Políticas, Relume Dumará, UFRJ, Nucleo de Antropologia política, 2001.

COSTA, Márcio. FERREIRA, Márcia. Desenvolvimento local e participação popular: a experiência do Pacto Novo Cariri. Cadernos Gestão e Cidadania, v.15, n.56. São Paulo, 2010.

DELLA PORTA, Donatella; VANUCCI, Alberto. The hidden order of corruption: an institutional approach, Ashgate, USA, 2012.

DICIONÁRIO MICHAELIS. Verbete politicagem. Disponível em: < http://michaelis.uol.com.br/moderno/portugues/index.php?lingua=portuguesportugues\&palavra=politicagem $>$. Acesso em março de 2017.

ELIAS, Norbert. Introdução a sociologia. Edições 70, Lisboa, Portugal, 2014. 
FAVARETO, Arilson; ABRAMOVAY, Ricardo; OLIVEIRA, Maria do Carmo; DINIZ, João; SAES, Beatriz. Desenvolvimento territorial em uma região do semiárido brasileiro do Nordeste Brasileiro - para além das transferências de renda. Documento de trabalho n'83. Programa Dinâmicas Territoriales Rurales. Rimisp- Centro Latinoamericano para o desarollo rural, Santiago, Chile, 2011, p. 1-29.

GOFFMAN. Erving. A representação do eu na vida cotidiana. Petrópolis, Vozes, 1971 HALL, Peter; TAYLOR, Rosemary. As três versões do neoinstitucionalismo. Revista Lua Nova, N.58, 2003, p. 193-223.

JORNAL SEBRAE BOLSA DE NEGOCIOS. Ano III, nº14, SEBRAE Paraíba, 1999.

LUKES, Steven. Verbete anomia. In: OUTHWAITE, W; BOTTOMORE, TOM (Ed.) Dicionário do pensamento social do século XX. Rio de Janeiro, Editora Zahar 1996, p. 20.

MARESCA, Sylvain. La représentation de la paysannerie. In: Actes de Recherche em sciences sociales, V. 38, mai 1981, p. 3-18.

MENESES, Valdênio. Associativismo e caprinocultura: políticas públicas e politicagem" no cariri paraibano. Dissertação apresentada no Programa de PósGraduação em Ciências Sociais-PPGCS, UFCG, Campina Grande, 2014a.

GOMES, Ramonildes. Mediação Social em projetos de desenvolvimento: os ADRS e a caprinocultura leiteira no Cariri Paraibano. In: NEVES, D.; GOMES, R. A.; Quadros institucionais em políticas públicas. Campina Grande, Eduepb, 2014b, p. 185-208.

. Entre "miunça" e caprinovinocultura: as cotas do PAA/Leite e os usos sociais da pecuária caprina. Revista Raízes, V.35, N.2, Jul-Dez, 2015, p. 67-82.

MENEZES, José Rafael de. Patriarcas da Alagoa de Monteiro. Recife, Ed. Universitária da UFPE, 1992.

MENEZES, José Rafael de, O testemunho dos bem-nascidos. Recife: Editora Bagaço, 1997.

NEVES, Delma Pessanha. O associativismo e a imposição do agricultor solidário. In: II Jornada de Estudos em Assentamentos Rurais, Campinas: Unicamp, 2005.

. Mediação social e mediadores políticos. In: NEVES, D.P. (Org.)

Desenvolvimento social e mediadores políticos. Porto Alegre/Brasília: Editora da UFRGS/PGDR, 2008, v. 1, p. 21-44.

PERISSINOTO, Renato; CODATO, Adriano. Dossiê: Elites políticas. Revista de sociologia e política. Curitiba v;16, n38, jun, 2008, p. 7-15.

RIETVIELD, João Jorge. Na sombra do Umbuzeiro: história da paróquia de São Sebastião do Umbuzeiro. João Pessoa: Imprell, 1999. 
SARDAN, Jean Pierre. Antrophologie et développement: essai en socio-antrophologie du changement social. Paris. Éditions Karthala, 1995.

BLUNDO, Giorgio. Semiologie populaire de la corruption. Politique Africaine, $\mathrm{N}^{\mathrm{o}} 83$, 2001c, p. 98-114.

2001b, $\mathrm{N}^{\circ} 83$, p. 8-37.

La corruption quotidienne en Afrique de l'Ouest, Politique Africaine,

SILVA, Miriam. Reforma agrária de mercado ou atualização do clientelismo? O

Programa Nacional de Crédito Fundiário e o assentamento de famílias sem-terra no Cariri Ocidental Paraibano. Dissertação de mestrado apresentada no Programa de PósGraduação em Ciências Sociais (PPGCS), UFCG, Campina Grande, 2012.

SOUZA, Bartolomeu ; SUERTEGARAY, Dirce; VIANA DA LIMA, Eduardo (2010) Políticas públicas, uso do solo e desertificação nos Cariris velhos (PB/Brasil). Scripta Nova. Revista Electrónica de Geografía y Ciencias sociales. XIV, $\mathrm{n}^{\circ} 311$, Barcelona: Universidad de Barcelona, Disponível em <http://www.ub.es/geocrit/sn/sn311.htm > Acesso em agosto de 2019.

SOUZA, Jessé. A tolice da inteligência brasileira - ou como o país se deixa manipular pela elite. 1. ed. São Paulo: Leya, 2015.

VITRINE DO CARIRI. Arquivos Disponível em < http://www.vitrinedocariri.com.br/index.php?option=com_content\&task=view\&id=201 $02 \&$ Itemid $=84>2008$.

Recebido em 15/05/2018.

Aceito para publicação em 16/06/2019. 